most family doctors do not understand what the Minister has in mind.

If the G.P. is to provide contraceptive services, two problems are at once apparent. Firstly, in the average practice and particularly in young communities, there will be a staggering increase in the workload. Secondly, there is increasing criticism that family dociors have less time for their patients; family planning requires special skills and is unusually time-consuming. The involvement of the G.P. in family planning under the N.H.S. may be a social and political ideal, but while the unwanted birth rate may fall, so may the time devoted to the care of the sick and those in need.

The availability of "free" contraception is not in question. The ability of G.P.s to cope with this extra burden is in doubt.-I am, etc.,

IAN G. HAMILTON

Harlow,

Essex.

SIR,-It was with some misgiving that I read in my morning paper that as from 1 April 1974 all contraceptives are to be made available on National Health Service prescription.

Some seven months ago my partner and I found that the number of women in our practice on the pill was assuming such proportions that we were unable to be as thorough in our six-monthly check-ups as we wished. We therefore decided to employ on a sessional basis a woman doctor who devotes all her available time to family planning work. The result has been most encouraging and the $75 \mathrm{p}$ for prescribing the pill has been a great help in her remuneration.

Can I take it that as from 1 April 1974 family planning will be yet another item the general practitioner must carry out with no extra remuneration? If so, I am sure a great many G.P.s will discontinue any form of regular examination for these women. Even at the present time numerous women arriving in this area have been astonished to learn that they are unable to obtain a repeat prescription without an examination.

So far as condoms are concerned, I did not study medicine with the ideas of supplying these articles. If the general public are to have condoms on the N.H.S. I suggest that family planning clinics supply them, or possibly the local health or welfare departments. As a medical examination is not necessary before a condom is worn I do not propose to issue prescriptions for these articles and feel that many G.P.s will follow suit.-I am, etc.

Faversham

J. CANTOR

SIR,-From 1 April 1974 oral contraceptives (and other contraceptive devices) will be available on prescription subject to the ordinary charges. This raises some interesting points.

General practitioners will now have a great deal of extra work thrust upon them. They will have to carry out regular checks on all women on the pill. The side effects are far from negligible, ranging from rapid weight increase to thromboembolic complications.

An entirely new precedent has been created in that the family doctor will be expected to prescribe on demand, and for social reasons, a potentially dangerous drug. Cases have already occurred where a member of the profession has had to face the courts when a patient for whom he has prescribed oral contraceptives has died as a result. Should every woman demanding the pill be asked to sign a statement that she takes it at her own risk? Doctors are entitled to some such protection.-I am, etc.,

Lytham St. Annes, Lencs.

T. J. BURKE

SIR,-Contraception on the N.H.S. from April 1974. Why not now?-I am, etc.,

Pulborough, Susser.

W. D. Hosknng

\section{Holiday Cruises}

SIR,-With the growing popularity of package tour holidays an ever-increasing number of people are embarking on holiday cruises each year. Many of these are elderly and infirm and some have been encouraged by their family doctor to take a sea voyage to convalesce from a recent debilitating illness. It is most important that such individuals should take with them full medical reports of their condition and current medications so that the ship's doctor is aware of the clinical situation should a deterioration in health occur while at sea.

The majority of British shipping companies have medical services based ashore whose medical staff are available for advice and who are familiar with the medical problems of passengers at sea. They are usually able to ensure medical support aboard a ship, together with special facilities such as diet or a wheelchair, which can be reassuring to a passenger and add to the enjoyment and safety of the holiday.-I am, etc.,

\section{P. O. OLIVER}

Group Medical Director

Cunard Steam-Ship Company Ltd., Southampton

\section{Compulsory Powers to See Case-notes}

SIR,-The medicolegal report (10 March, p. 623) and the letter from the Secretary of the Medical Protection Society (24 March, p. 746) are slightly puzzling.

Ever since the National Health Service Act the position with regard to destruction of the patient's records has been statutory, although it was modified a little by the Public Records Act, 1958 (see circular HM (61) 73').

Briefly, the position now is that no part of any patient's records, however trivial, may be destroyed until six years after the conclusion of treatment unless the patient should die in hospital, when the period is reduced to three years. At the expiry of that period the general day-to-day notes and the $x$-ray films may be destroyed, but the case summaries must be kept indefinitely. Presumably if before the lapse of six years a patient should re-attend at the hospital then the time would start to run again from this date and the older records would be still fully preserved. I hardly think that it is reasonable to ask for the keeping of records much beyond this statutory minimum. The sheer physical problems of storage become very considerable at a large hospital.-I am, etc.,

\section{Queen Mary's Hospital,
Sidcup, Kent}

H. GLYN JONES

1 National Health Service, Preservation and Destruction of Hospital Records, H.M. (61) 73,

\section{School Eye Clinics}

SIR,-While welcoming the review by Dr. R. M. Ingram (3 February, p. 278) I would strongly disagree with the suggestion to move the school eye clinics to inside a hospital. First, the school eye clinic is a development of the public health services and as such its role is mainly preventative. Their officers are expected to be on the look out for eye troubles, to chase up defaulters, and to ensure if possible that glasses are in fact obtained and worn when ordered. This is quite different, and rightly so, from what pertains in a hospital clinic where the patient should firstly be seeking help in some respect; where, though appropriate treatment or advice is offered, it is up to the patient whether he accepts it or not-unsolicited advice is not uncommonly ignored. Also if the patient does not voluntarily return for follow-up he is unlikely to value his visit if finally persuaded to return.

One result immediately following the introduction of the school eye service in 1910, and attributed to it, was the marked decline in the incidence of divergent strabismus. This was because myopia was discovered early and corrected by glasses. One wishes that the preventative aspects of convergent strabismus and amblyopia were as good. Dr. P. A. Gardiner (3 March, p. 552) shows what can be done, but unfortunately it is the exception. Convergent strabismus generally arises much younger, around two years, and I have heard of school clinics that do not see preschool children. The sooner it arises the sooner it is necessary to get ahead with treatment, but there is little (apart from operation) which cannot be done in a school clinic with some orthoptic help. This is an age when the child or parent may be put of by the thought of going to hospital. I believe it would be most retrograde to expect them to do so when treatment can be done in the less frightening atmosphere of the school clinic. By all means have a separate children's eye clinic in the hospital for those whose conditions necessitate hospital treatment, but I do not think this is necessary or desirable for the ordinary school eye clinic children. Nor do I think it wise to push children whose only trouble is refractive error out of the school clinic service after the first visit, as, though there are other services by ophthalmic medical practitioners and opticians, they have no means of chasing up defaulters. I know of children of both sexes who keep quiet about their visual difficulties just because they do not wish to wear glasses, and of parents who agree with them or are under their thumb, or who do not bother or are too busy or forgetful to see about the child's glasses and follow-up.

Of course arrangements vary in different regions. The work need not be undertaken by a consultant, and a registrar, even a senior registrar, has scarcely the right experience for it. In our area serving a popula- 
tion of about $\frac{3}{4}$ million there are some 34 school clinic sessions per week, and the hospitals, already full, just could not fit in the extra sessions. Fortunately all but four of these clinics are run by S.H.M.O.s or the equivalent who have also assistant sessions at the regional eye unit and our six subsidiary hospitals, so that an adequate relationship of the two services is obtained.am, etc.,

Romford, Essex

John Primrose

\section{Practice in the United States}

SIR,-I am a British paediatrician in the United States on a one year fellowship. Before he comes to the United States a hospital doctor needs the E.C.F.M.G. certificate. He may then be under the impression that no further qualifications are necessary during the course of a one-year stay here.

Many doctors in the past have discovered on arrival in America that they cannot survive on their fellowship remuneration alone and have wanted to indulge in the universal and lucrative practice of "moonlighting." But unless the doctor arrives in the U.S. as a permanent immigrant, as opposed to an exchange visitor, he is precluded from taking the new examination known as F.I.E.X. (Federal Licensing Examination), which is essential if he is to indulge in work outside his own hospital. I wish to bring to the notice of my colleagues the limitations of coming as an exchange visitor and my realization that the E.C.F.M.G. qualification gives one only minimal rights.-I am, etc.

Donald Bentley

The Children's Hospital Medical Centre,
Boston, Massachusetts

\section{Outpatient Appointments System}

SIR,-Since the outpatient appointment system has been critically examined in various quarters my experience of it as a consultant physician might be of some interest. From early June 1971 to mid-July 1972 I kept a private record of all attendances of new patients at my general medical clinic. This amounted to 50 working weeks, four being taken as holiday and three omitted because of poor travelling conditions for patients.

I have used my appointment system continuously for five years. The clinic begins at 8.30 a.m., when follow-up patients are seen. Appointments for new patients, who are seen by myself, are made for the following times: 9.20 a.m. (two patients), 10 a.m., 10.15 a.m., 10.30 a.m., and 10.45 a.m. Afternoon appointments are made for 1.30 p.m. (two patients), 2.15 p.m., 2.30 p.m., 2.45 p.m., 3.15 p.m., 3.30 p.m., and 3.45 p.m. The clinics are always finished by 11.30 a.m. and 4.30 p.m. at the latest. In practice this system allows for 20 minutes per new case. There is no significant waiting list. A patient failing to attend is no sent a second appointment, but the patient's general practitioner is asked to instruct the patient to apply for a further appointment if this is considered necessary.

Cancellations of appointments 24 hours or more before the appointed time are not recorded as failures to attend. Cancellations within 24 hours are counted as failures unless the vacant period was used by another patient. All 50 morning clinics were full with one exception, when there were only three appointments. Seven afternoon clinics were not required and a further seven only partially filled, mainly round Christmas, Easter, and in August. There were appointments for 297 patients, and of these 11 failed to attend. The appointment of six of the 11 was for 9.20 a.m. Fourteen patients were between 10 to 25 minutes late for their appointment, 12 between 25-40 minutes late, and three over 40 minutes late; lateness was commonest at the early hour. There were 315 afternoon appointments made : 19 patients failed to attend, eight were $10-25$ minutes late, and two over 25 minutes late. Any lateness of less than 10 minutes was recorded as being on time. The reasons for lateness were not analysed in detail, but in about one quarter of the cases the delay was due to the ambulance service. This is not a criticism. The ambulance service has made every effort to co-operate. Rather it shows the problems of integrating an individual clinic with ambulance centres serving a group of hospitals and many clinics simultaneously. The remainder of the patients' reasons varied. A not uncommon statement to the sister was one of flusterid surprise that there was not to be the usual hour's waiting time.

In summary, 612 appointments were made, 30 were not kept, and 39 patients arrived ate enough to cause dislocation of the clinic. Thus in any list of nine appointments some waste of the consultant's or the patient's time can be expected. To try to avoid this I have taken the following steps: (1) No second appointments are made for non-attenders, except by request. (2) Two patients are allotted to the first appointment time in the morning and afternoon in the hope that one will be on time, but a slightly longer consultation period is allowed. (3) The appointment times are at 15-minute intervals, but a gap of $\mathbf{3 0}$ minutes is left in the middle of a longer clinic to allow for catching up if necessary. I conclude that a perfect system is impossible, but, equally, the waiting of many hours by patients or the wasting of many hours by consultants are both unnecessary.-I am, etc.,

St. Catherine's Hospital,

S. COPE

Birkenhead

\section{Toxicity of Benorylate}

SIR,-The request of Dr. R. E. HopeSimpson (3 February, p. 296) for information from other clinicians who might have had similar experiences to his own regarding the rapid onset of salicylism in patients receiving benorylate was met by a letter from Dr. K. Hingorani (17 February, p. 418), who expressed his confidence in benorylate as an antirheumatic drug. These letters prompt me to report the following observations.

Although tinnitus and some loss of hearing are to be expected in some patients when salicylates are administered at dosages intended to achieve an anti-inflammatory effect it has been my experience that the administration of benorylate at the recommended dosage of $4 \mathrm{~g}$ twice daily is associated with a greater frequency and earlier onset of symptoms of salicylism. In 20 patients with defined rheumatoid arthritis benorylate was administered as the sole antiinflammatory drug, and 11 patients developed severe tinnitus and deafness after the second dose of the suspension. Ten of these patients agreed to resume the compound at $2 \mathrm{~g}$ thrice daily after they had recovered from their symptoms, plasma salicylate levels being monitored three hours after each dose. However, nine of them developed similar symptoms after the third dose (mean time of onset after first dose, 18.2 hours) and were withdrawn from benorylate therapy. At the time of onset of tinnitus the mean total plasma salicylate concentration was $2.7 \pm 0.2$ (S.D.) $\mathrm{mmol} / 1$. Three days after cessation of all symptoms of salicylism the nine patients were given soluble aspirin at a dosage of $1.2 \mathrm{~g}$ four times a day and plasma salicylate concentrations were measured as previously. The mean total plasma salicylate concentration did not exceed $1.8 \pm 0.15 \mathrm{mmol} / \mathrm{l}$. at any time, and only one of the nine patients developed salicylism, which occurred on the fifth day of this regimen.

It has been demonstrated that at a total plasma salicylate level of $0.1 \mathrm{mmol} / 1$. approximately $1 \%$ of the drug is in the free form; this increases to $10 \%$ at $1 \mathrm{mmol} / 1$. and $25 \%$ at $3 \mathrm{mmol} / 1$. Toxicity rather than clinical effectiveness appears to be associated with the accumulation of unbound salicylate. Expected free salicylate concentrations, based on the total plasma levels measured, would give approximate values of 0.65 $\mathrm{mmol} / 1$. on benorylate and $0.15 \mathrm{mmol} / 1$. on aspirin. Whereas some human albumin molecules appear to possess fewer binding sites than others ${ }^{3}$ the present data suggest that this is unlikely to be a factor in the greater frequency and earlier onset of tinnitus and deafness with benorylate compared with equivalent dosages of aspirin. The abnarent half-time of salicvlate elimination following oral administration of aspirin is dose-dedendent, ${ }^{4}$ while benorvlate's rate of metabolism in man is slower than that of asoirin. ${ }^{5}$ It seems that there are susceptible individuals who experience tinnitus and deafness quite rapidly on the twice-daily dosage of benorylate but do not experience similar effects with equivalent dosage of aspirin. The study is being extended to evaluate the various mechanisms which reoulate plasma salicylate levels after the administration of benorylate in this group of patients.-I am, etc.,

MANSEL AYLWARD

Recearch Division

Merthyr Gereral Hospital, 1 Davison, C., and Smith, P. K., Fournal of 2 Smith, M. J. H., and Dawkins. P. D. Foumal of Pharmacy and Pharmarolooy, 1971. 23. 729.
Moran. C. I., and Walker. W. H. C., Biochemical Pharmacolony, 1968, 17. 153.

4 Levy, G and Lonerds, I ed. M. I. Smith and P. R. ' Smith. New York, Inter Science, 1966. 5 Robertson, A. VII Eurobean Rheumatology
Congress, 1971. Abstract No. 45/4.

Plasma Digoxin Concentration in Children with Heart Failure

SIR,-The paper by Dr. J. E. Cree and others (24 February, p. 443) is a useful contribution to the attempts being made to find a rational basis for the dosage regimen in children of varying ages.

However, the single estimations they made were of the plasma digoxin level after at least five days of maintenance therapy. This showed reasonable levels (in comparison with adult levels) on the maintenance regimen they followed. They do not, however, give any details of the blood levels achieved during the initial 24 hours of 